\title{
Calidad de Materiales Textiles: Determinaciones instrumentales de las propiedades físicas de la fibra de algodón desmotada.
}

Mgtr. Ing. Emilio Fabián Scozzina $\left(^{*}\right)$

Palabras Claves: Algodón, Textiles, Fibras Naturales, Determinación Instrumental.

\section{Resumen.}

El objetivo de esta publicación, es presentar un resumen de la aplicación real de las normas internacionales que se utilizan en determinaciones instrumentales de las propiedades físicas de la fibra de algodón desmotada.

\section{Introducción.}

Enelmercadodelnacionaleinternacional del algodón, resulta indispensable contar con la evaluación tecnológica de la calidad de la fibra de algodón, comúnmente llamada "Clasificación", esto no es más que la aplicación de procedimientos normalizados e instrumentales para la medición de propiedades físicas y mecánicas de la fibra de algodón, que afectan la calidad de los productos textiles y sus manufacturas.

Este procedimiento se realiza a través de instrumentos de medición de alto o medio volumen llamados comúnmente (H.V.I / MVI) dentro del sector textil. El significado de estas siglas en ingles es instrumento de alto volumen, o instrumento de medio volumen, esta propiedad se refiere a la cantidad de muestras procesadas por unidad de tiempo, de ahí el tipo de instrumento.

E1 método MVI para clasificación de las fibras de algodón (Instrumentos de Medio Volumen), es poco frecuente utilizarlo en nuestro país, los más común es las empresas tengan equipos con mayor velocidad tipo HVI (Instrumentos de Alto Volumen) que hacen estas operaciones en forma automática, sacrificando en algún 
caso precisión. Los instrumentos más comunes de este tipo son Uster,Premier, Statex,'Tex'Techno.

2. Condiciones ambientales de ensayo: Norma ISO 139.

Para poder ensayar las fibras de algodón se hace necesario cumplir con 1a Norma Técnica ISO 139:2005 "Textiles. Standard atmospheres for conditioning and testing". Esta norma internacional define las características de una atmósfera normal para el acondicionamiento y la determinación de las propiedades físicas y mecánicas de los textiles, que este caso se fijan parámetros de temperatura y humedad de: $20^{\circ} \mathrm{C}+-2^{\circ} \mathrm{C}$ y $65 \mathrm{HR} \%+-4 \%$.

Para lograr este acondicionamiento ambiental, se hace necesario calcular el balance térmico y la climatización requerida en la sala donde se destinara el laboratorio de textiles. Esto se proyecta según su ubicación geográfica de laboratorio, en base a las condiciones climáticas locales y datos estadísticos.

Con ello se determina el grado de aislación térmica de las paredes y techo, además dimensionar el equipamiento que realizara el control de temperatura y humedad, mediante un sistema enfriador, que cuenta con resistencias eléctricas y un humidificador, todo ello integrado en un sistema climatizador, que permite el control de la variables termodinámicas Temperatura y Humedad para cumplir el requerimiento ISO.

\section{Metodología Utilizada.}

El método para realizar las distintas determinaciones se encentra documentado en la Guideline for Standardized Instruments Testing of Cotton Date of Inssue V1.1. May 2012 Version Long. ITMF: (Internacional Commite on Cotton Testing Method) y ICAC: (Task Force on Commercial Standarization of Instruments Testing of Cotton.)

Como primera etapa se deben climatizar las muestras de fibras de fibras de algodón en una ambiente ISO $139\left(20^{\circ} \mathrm{C}+-2^{\circ} \mathrm{C}\right.$ y 65 HR \%+-4\%), durante 24 horas como mínimo, para estabilizar su contenido de humedad, antes de realizar los ensayos.

Se procede a determinar el Grado de Color (CG) de la fibra mediante un espectrofotómetro de esfera DL65-8 ${ }^{\circ}$, que proporciona los valores $L^{*}, a^{*} b^{*}$, Reflectancia \% RD y Amarillez +b. Tomando como base la carta de Nickelson-Hunter para la fibra de algodón de referencia Upland USDA.

El paso siguiente es determinar la Finura y Madurez de la fibra de algodón mediante un instrumento, de flujo de aire, el Micronaire. El micronaire es una medida de finura y madurez de la fibra de algodón, se utilizan instrumentos que trabajan con diferencia de presión y caudal de aire, sobre una obstrucción de fibra de algodón. (Son los llamados métodos de limitación de caudal).

El índice de madurez es un valor relativo al desarrollo de la fibra y está directamente relacionado con el Micronaire. Indica el espesor de la pared de celulosa dentro de una muestra de algodón y se expresa en porcentaje. 


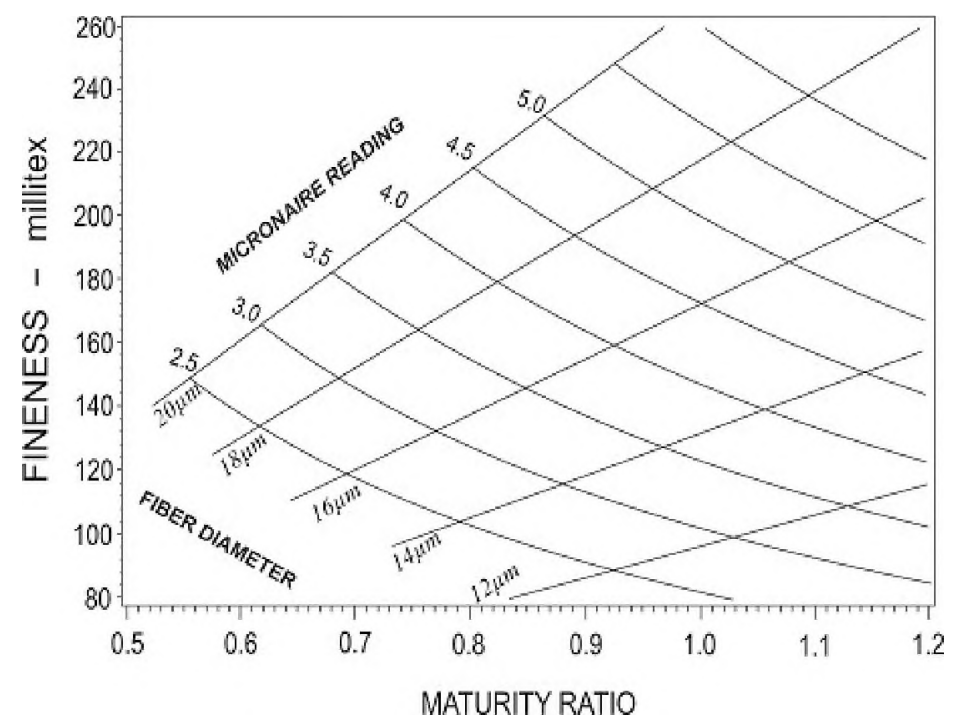

Gráfico No1 La gráfica muestra la relación entre el micronaire, la finura de la fibra, la tasa de madurez y el diámetro de la fibra teórico

Todos los instrumentos, se calibran fibras de algodón se acondiciona para ser con un material de referencia y se ingresadasalMVI, queinstrumentalmente utilizan fibras de algodón desmotado determina los siguientes parametros: provenientes del USDA. La muestra de

\begin{tabular}{|l|l|l|}
\cline { 2 - 3 } \multicolumn{1}{l|}{} & Determinación & Unidad \\
\hline 1 & Mean Length & $\mathrm{mm}$ \\
\hline 2 & Span Length 50\% & $\mathrm{mm}$ \\
\hline 3 & Span Length 25\% & $\mathrm{mm}$ \\
\hline 4 & Span Length 2,5\% & $\mathrm{mm}$ \\
\hline 5 & Upper Half ML & $\mathrm{mm}$ \\
\hline 6 & Upp. Quart. ML & $\mathrm{mm}$ \\
\hline 7 & Short Fibre Cont. & $\%$ \\
\hline 8 & Short Fibre Index & $\%$ \\
\hline 9 & Uniformity Ratio & - \\
\hline 10 & Uniformity Index & - \\
\hline 11 & Bundle Weigth & $\mathrm{mg}$ \\
\hline 12 & Maximun Force & $\mathrm{N}$ \\
\hline 13 & Strength & $\mathrm{g} / \mathrm{Tex}$ \\
\hline 14 & Elongation Fmax & Fmax- $\%$ \\
\hline 15 & Fibrograma & $\mathrm{Grafico}$ \\
\hline
\end{tabular}

Tabla 1: Determinaciones realizadas con instrumental MVI de origen alemán. 


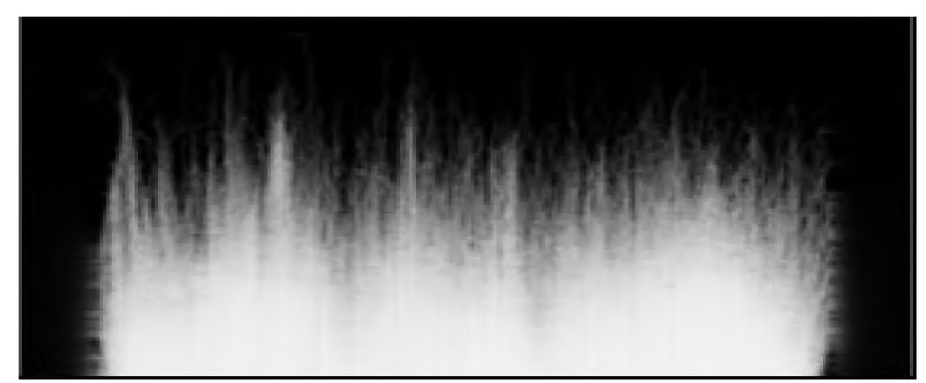

Gráfico No2 Fotografía de la muestra de fibras de algodón que es tomada por la cámara CDD de un equipo MVI, para realizar las determinaciones del fibrograma.

Las mediciones impurezas en las proporciona otros datos adicionales, como ser muestras de algodón desmotado, como la limpiabilidad, y la eficiencia de las limpiezas ser de polvillo, neps, fragmentos, semillas sucesivas. Estas determinaciones se realizan e impurezas presentes en las fibras de de forma gravimétrica, complementadas, algodón se determinan con un instrumento con software para análisis de imágenes, por (Microdust -Trasch Analyser), este equipo reconocimiento de colores y formas.

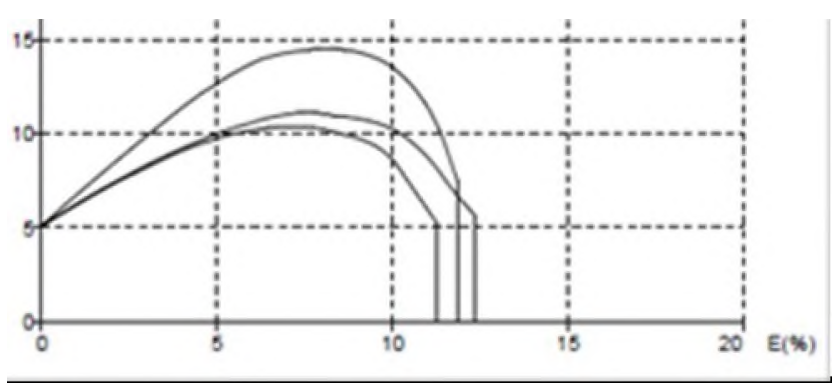

Gráfico No3 Fotografía de la muestra un ensayo de tracción realizado con instrumento $M V I$. Valores tipicos: Estiramiento de rotura Std. 3-9.5\%. Resistencia a la rotura: Estándar 27-44 y

\section{El Autor.}

El autor, diseño el laboratorio textil en una provincia algodonera por excelencia. de Centro INTI Chaco, con capacidad de El laboratorio cuenta con trazabilidad y mediciones MVI. Este laboratorio de calidad sus procesos están dentro las Normas ISO de fibras resulta importante para posicionar al 17.025 . La presente publicación esta basada país dentro de la cadena de valor de la fibra en la presentación Tecno INTI 2017 trabajo de algodón y los productos textiles derivados, No118 del autor. 


\section{Propiedades de la fibra de algodón:}

\begin{tabular}{|c|c|}
\hline Efecto de los ácidos. & $\begin{array}{l}\text { Se desintegra con los ácidos diluidos calientes o ácidos } \\
\text { concentrados fríos. No lo afectan los ácidos débiles fríos. }\end{array}$ \\
\hline Efecto de los álcalis. & Hinchazón (mercerización) en cáustico, pero sin daño. \\
\hline $\begin{array}{l}\text { Efecto de los solventes } \\
\text { orgánicos. }\end{array}$ & Resistente a la mayoría de los solventes industriales y del hogar. \\
\hline $\begin{array}{l}\text { Efecto de otros } \\
\text { químicos. }\end{array}$ & $\begin{array}{l}\text { Se blanquea por hipocloritos y agua oxigenada, se oxida en } \\
\text { oxicelulosa. Se infla y se desintegra en hidróxido cupramónico. }\end{array}$ \\
\hline Efecto del calor. & $\begin{array}{l}\text { Altamente resistente a la deformación térmica y degradación. } \\
\text { Principio de descomposición en el aire (TGA) } 290^{\circ} \mathrm{C} \text {. Temperatura } \\
\text { de planchado sin peligro } 218^{\circ} \mathrm{C} \text {. Toma un color amarillo después de } \\
5 \text { horas a } 120^{\circ} \mathrm{C} \text {. }\end{array}$ \\
\hline $\begin{array}{l}\text { Absorción de la } \\
\text { humedad. }\end{array}$ & $7 \%$ (condiciones estándar). \\
\hline $\begin{array}{l}\text { Poder de absorción de } \\
\text { la humedad. }\end{array}$ & $24-27 \%$ a $95 \%$ R.H. \\
\hline $\begin{array}{l}\text { Colorantes } \\
\text { comúnmente usados. }\end{array}$ & $\begin{array}{l}\text { Directos, colorantes a la cuba, colorantes azoicos, básicos, } \\
\text { colorantes mordentes, pigmentos, sulfuro, reactivos. }\end{array}$ \\
\hline Recuperación elástica. & $\begin{array}{l}74 \% \text { de recuperación después de un } 2 \% \text { de estiramiento. } \\
45 \% \text { de recuperación después de un } 5 \% \text { de estiramiento. }\end{array}$ \\
\hline Identificación a la llama. & $\begin{array}{l}\text { Una vez encendida la fibra deja una ceniza fina y gris y no deja } \\
\text { gotas. La apariencia longitudinal es rectilínea y parece cinta con } \\
\text { circunvoluciones. Se disuelve en } 80 \% \text { de ácido sulfúrico frío. }\end{array}$ \\
\hline $\begin{array}{l}\text { Resistencia a la } \\
\text { tracción. }\end{array}$ & $44,000-109,000$ psi \\
\hline
\end{tabular}

Tabla N² Propiedades físicas de la fibra de algodón. 


\section{Bibliografía.}

Norma Técnica ISO 139:2005 “Textiles. Standard atmospheres for conditioning and testing". https://www.iso.org/ .

ICAC Task Force Commercial Standardization of Instrument Testing of Cotton and ITMF International Committee on Cotton Testing Methods (ICCTM) Guideline for Standardized Instrument Testing of Cotton. Date of issue: V1. -May 24, 2012 www.csitc.org

ISO /IEC 17025 General Requirements for the Competence of Testing and Calibration Laboratories V 2005. https://www.iso.org/

USDA Guidelines for HVI testing (Based on version (June 2005). https://www.usda.gov/ USDA AMS Agricultural Handbook 566
The Classification of Cotton Version 2001. https://www.usda.gov/

ASTM D 5867 Standard Test Methods for Measurement of Physical Propieties of Cotton Fiber by High Volume Instruments current version 2005. https://www.astm.org/

ASTM D 1776 Practice for Conditioning and Testing Textiles (current version 2008). https://www.astm.org/

ASTM D 7410 Standard Practice for Qualification of Cotton Classification Instruments for Cotton Marketing. Current version 2008. https://www.astm.org/ 